\section{Removal of Internally Deposited Radionuclides by Triethylenetetraamine-hexaacetic Acid}

INCREASING the number of donor groups in chelating agents can give rise to the formation of more stable chelates ${ }^{1-3}$ and, therefore, to a higher mobilization of internally deposited trivalent and other metal ions of higher valency. This has been demonstrated with ethylenediamine - NNN' $\mathbf{N}^{\prime}$ - tetraacetic acid (EDTA) and diethylenetriamine-NNN' $N^{\prime} N^{\prime \prime}$-pentaacetic acid (DTPA) ${ }^{4,5}$, that is, with chelating agents with 6 and 8 donor groups respectively. For this reason extension of this work to the 10-dentate triethylenetetraamine $-\mathrm{NNN}^{\prime} \mathrm{N}^{\prime} \mathrm{N}^{\prime \prime} \mathrm{N}^{\prime \prime \prime}$ - hexaacetic acid (TTHA) seemed to be worth while.

Carrier-free cerium-144, yttrium-91 or strontium-85 was injected intravenously in rats 7-9 weeks old averaging $165 \mathrm{gm}$. in weight. The chelating agents (by courtesy of J. R. Geigy, S.A., Basle) were given immediately or at different time-intervals after the injection of the nuclide. As shown in Table 1, TTHA reduces the radiocerium content of the skeleton more effectively than DTPA, when given simultaneously or immediately after the administration of the nuclide. In the liver, however, under the same conditions, DTPA is more effective than TTHA. The comparative higher effectiveness of DTPA in mobilizing deposited radiocerium from the liver becomes still more pronounced if the chelating agent is administered after longer time intervals, whereas the superiority of TTHA over DTPA in the removal of radiocerium from the skeleton vanished. Analogous results have been obtained for radioyttrium (Table 2); but neither TTHA nor DTPA had any effect on the mobilization of radiostrontium.

The causes for the observed differences in the behaviour of these two chelating agents are not yet understood. It may be assumed tentatively that TTHA forms to some extent polynuclear colloidal chelates which may be metabolized differently from the smaller molecules of the $1: 1$-DTPA chelates. The greater effectiveness of TTHA as compared with DTPA in the removal from the skeleton-the critical organ for most radionuclides of radiocerium and radioyttrium can be of therapeutical value in certain cases and justifies further investigations on other radionuclides, especially plutonium.
A. Catsch
D. SCHINDEWOLF-JORDAN

Institut für Strahlenbiologie,

Kernforschungszentrum,

Karlsruhe 1.

${ }^{1}$ Anderegg, G., Nägeli, P., Müller, F., and Schwarzenbach, G., Helv. Chim. Acta, 42, 827 '(1959).

${ }^{2}$ Durham, E. J., and Ryskiewich, D. P., J. Amer. Chem. Soc., 80, 4812 (1958).

${ }^{3}$ Harder, R., and Chaberek, S., J. Inorg. Nucl. Chem., 11, 197 (1959). Heller, H. J., and Catsch, A., Strahlentherapie, 109, 464 (1959).

${ }^{5}$ Catsch, A., Fed. Proc., Supp. 1961 (in the press), which includes further references.

\section{Incorporation of Phosphorus-32 into Urinary Concretions forming on Zinc Implants in Rat Bladders}

IT has been proposed that labelling with radioisotopes might be useful in studying the rate of formation of urinary calculi in experimental animals as a function of environmental conditions. The proposal was based on the fact that in siliceous urinary stones of bovine origin, which contain traces of phosphorus and calcium, diffusion and subsequent exchange of phosphorus-32 and calcium-45 with the non-radioactive counterparts of the stone material do not readily occur across the mucoprotein laminations ${ }^{1}$. It was felt that if stone formation occurs layer by layer, short-term massive administration of phosphorus-32 to an experimental animal forming a laminated calculus would result in incorporation of the radionuclide into a single or limited number of laminations, and that subsequent exchange into other laminations would be negligible. Further, if administration of phosphorus-32 were then stopped, and exchange from other parts of the body did not cause significant levels of phosphorus-32 in urine, subsequent laminations would be relatively free of label. Therefore periods of exposure to various environmental conditions could be alternated with periods of administration of isotope, and the amount of material deposited between the laminations

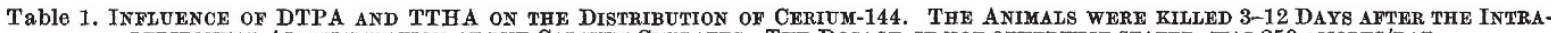
PERITONEAL AdMinistration OF THE CALCIUM Chelates. THE DOSAGE, IF NOT OTHERWISE STATED, WAS $250 \mu$ MOLES/RAT

\begin{tabular}{|c|c|c|c|c|c|c|c|}
\hline \multirow{2}{*}{\multicolumn{2}{|c|}{ Treatment }} & \multirow{2}{*}{$\begin{array}{c}\begin{array}{c}\text { No. of } \\
\text { animals }\end{array} \\
10 \\
10\end{array}$} & \multicolumn{5}{|c|}{$\begin{array}{l}\text { Per cent of control } \\
\text { Mean and flducial limits }(P=0.05)\end{array}$} \\
\hline & & & \multicolumn{2}{|r|}{ Liver } & Kidneys & \multicolumn{2}{|r|}{ Skeleton } \\
\hline 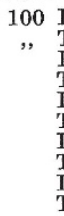 & 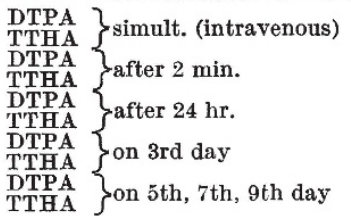 & $\begin{array}{l}10 \\
10 \\
28 \\
27 \\
22 \\
12 \\
13 \\
13 \\
18 \\
18\end{array}$ & $\begin{array}{r}0 \cdot 11 \\
0 \cdot 23 \\
1 \cdot 00 \\
1 \cdot 50 \\
21 \cdot 00 \\
33 \cdot 00 \\
28 \cdot 00 \\
55 \cdot 00 \\
11 \cdot 00 \\
29 \cdot 00\end{array}$ & $\begin{array}{l}(0 \cdot 08-0 \cdot 14) \\
(0 \cdot 17-0 \cdot 31) \\
0 \cdot 78-1 \cdot 30) \\
1 \cdot 30-1 \cdot 70) \\
(19 \cdot 00-24 \cdot 00) \\
(27 \cdot 00-40 \cdot 00) \\
(23 \cdot 00-33 \cdot 00) \\
(48 \cdot 00-63 \cdot 00) \\
(8 \cdot 40-14 \cdot 00) \\
(23 \cdot 00-36 \cdot 00)\end{array}$ & $\begin{array}{ll}14 & (9 \cdot 5-21) \\
14 & (9 \cdot 1-21) \\
19 & (16 \cdot 0-23) \\
16 & (14 \cdot 0-19) \\
54 & (43 \cdot 0-68) \\
64 & (53 \cdot 0-77) \\
86 & (63 \cdot 0-117) \\
86 & (68 \cdot 0-109) \\
70 & (53 \cdot 0-91) \\
74 & (58 \cdot 0-95)\end{array}$ & $\begin{array}{c}1 \cdot 3 \\
0 \cdot 45 \\
10 \cdot 00 \\
5 \cdot 20 \\
72 \cdot 00 \\
68 \cdot 00 \\
72 \cdot 00 \\
75 \cdot 00 \\
61 \cdot 00 \\
58 \cdot 00\end{array}$ & $\begin{array}{l}(0 \cdot 9-1 \cdot 8) \\
(0 \cdot 33-0 \cdot 62) \\
(9 \cdot 00-12 \cdot 00) \\
(4 \cdot 50-6 \cdot 10) \\
(64 \cdot 00-80 \cdot 00) \\
(62 \cdot 00-74 \cdot 00) \\
(67 \cdot 00-82 \cdot 00) \\
(67 \cdot 00-84 \cdot 00) \\
(53 \cdot 00-70 \cdot 00) \\
(52 \cdot 00-65 \cdot 00)\end{array}$ \\
\hline
\end{tabular}

Table 2. INfluence of DTPA and TTHA on the Distribution of Yrtrium-91. The ANimals Were killed 3-6 Days after the Intraperitoneal administration of the Calcium Chelates. The Dosage, if not otherwise stated, Was $250 \mu$ Moles/Rat

\begin{tabular}{|c|c|c|c|c|c|}
\hline \multirow{2}{*}{\multicolumn{2}{|c|}{ Treatment }} & \multirow{2}{*}{$\begin{array}{c}\text { No. of } \\
\text { animals }\end{array}$} & \multicolumn{3}{|c|}{$\begin{array}{l}\text { Per cent of control } \\
\text { Mean and fiducial limits }(P=0.05)\end{array}$} \\
\hline & & & Liver & Kidneys & Skeleton \\
\hline $\begin{array}{c}100 \\
, y\end{array}$ & 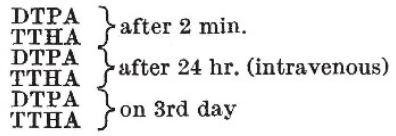 & $\begin{array}{r}12 \\
12 \\
8 \\
10 \\
13 \\
14\end{array}$ & $\begin{array}{ll}36 & (26-51) \\
42 & (28-62) \\
57 & (45-71) \\
54 & (44-65) \\
50 & (39-66) \\
61 & (47-79)\end{array}$ & $\begin{array}{ll}23 & (18-30) \\
25 & (18-33) \\
89 & (54-149) \\
68 & (43-107) \\
76 & (46-126) \\
88 & (54-144)\end{array}$ & $\begin{array}{rr}5 \cdot 7 & (4 \cdot 9-6 \cdot 6) \\
3 \cdot 9 & (3 \cdot 6-4 \cdot 3) \\
81 \cdot 0 & (74 \cdot 0-87 \cdot 0) \\
83 \cdot 0 & (77 \cdot 0-89 \cdot 0) \\
76 \cdot 0 & (70 \cdot 0-83 \cdot 0) \\
79 \cdot 0 & (74 \cdot 0-85 \cdot 0)\end{array}$ \\
\hline
\end{tabular}

